\title{
The Comparison Of Effectiveness Between Ginger Drinks And Dark Chocolateindecreasingdysmenorrhea
}

\author{
Paramitha Amelia Kusumawardani ${ }^{1, *}$, Cholifah $^{2}$ \\ ${ }^{1,2}$ Universitas Muhammadiyah Sidoarjo, Street Raya rame no 4 Pilang, Wonoayu, Sidoarjo, East Java, Indonesia \\ 1paramitha_amelia@umsida.ac.id* \\ *corresponding author \\ Submission date: 10 Juli 2018, Receipt date: 10 Oktober 2019, Publication date: 1 Juli 2020
}

\begin{abstract}
The aims of the study are to measure and obtain data change on dysmenorrhea in the group of ginger drinks and dark chocolateand to compare the effectiveness between ginger drinks and dark chocolate in decreasing dysmenorrhea. Dysmenorrhea disorders can be occur for several hours even up to several days and interfere daily activities. Approximately 15\% during menstrual dysmenorrhea has an impact on daily activities, requiring antianalgesic drugs and nearly 40\% of dysmenorrhea may require medical treatment and $8-10 \%$ are not attending school. The research design uses Quasi Experimental with one group pretest-posttest design. The result ofdifference between pretest and posttest valueobtained by using Paired Sample Test.The result of the research shows the correlation between intensity of dysmenorrhea and ginger drinks seen from significant value $\alpha 0.020<\alpha 0.05$ while the strength of the relation is medium which seen from correlation strength is 0.592 . Whereas there is no correlation between intensity of dysmenorrhea and dark chocolate seen from significant value $\alpha 0.421>\alpha$ 0.05 with low relation strength seen from correlation strength value 0,225. Based on the results, the researchers concluded that ginger drinks is more influential in decreasing dysmenorrhea than dark chocolate with $\alpha 0.020<\alpha 0.05$.
\end{abstract}

Keywords: ginger drinks, dark chocolate, dysmenorrhea

\section{INTRODUCTION}

Some dysmenorrhea case are most often complained by women of any age who experience menstruation, dysmenorrhea often accompanied by conditions that can aggravate such as cold sweats, dizziness, and even dysmenorrhea can cause fainting [1]. As many as $45-75 \%$ of young women will experiencedysmenorrhea before or during menstruation caused by uterine muscle spasms. Approximately $10 \%$ of women with dysmenorrhoea with severe scales and severe pain may cause the patient temporarily unable to carry on the activity. The percentage of menstrual pain cases in Indonesia is about 55\% and dysmenorrhea prevalence ranges from $45-90 \%$ among women of reproductive age. Pharmacologic or nonpharmacologic action / therapy should be given if dysmenorrhoea is not treated promptly so as to affect the individual's physical and mental function [2].

Providinganalgesic medications is one of pharmacologic therapy and nonpharmacologic therapy with herbal medicine, hypnotherapy, dark chocolate, relaxation, acupuncture and dairy products. In addition, herbal therapy can be done by using traditional medicines derived from plant materials such as soybeans, cloves, turmeric, cinnamon and ginger[3]. Ginger is a natural anti-inflammatory drug or pain 
relievers during menstruation. Ginger extract can suppress the release of prostaglandin and leukotrin in the endometrium resulting in strong contractions resulting in pain called dysmenorrhoea or menstrual pain [4]. One chemical content of gingerol is able to block prostaglandins contained in red ginger so prostaglandins can reduce pain during menstruation. In red ginger, there are several chemical components such as shogaol, zingerone and gingerolgivenphysiologic and pharmacological effects such as anticarionic, antioxidant, anti-inflammatory, analgesic, non-toxic and non-mutagenic and non-toxic, although obtained at high concentrations [5].

Several studies have mentioned the relationship of some nutrients with decreased levels of dysmenorrhea. Nutrients that can help relieve dysmenorrhea are calcium, magnesium and vitamins A, E, B6, and C. One of the non-pharmacological therapy in terms of nutrition that can be used as an alternative to overcome the pain during menstruation is black chocolate. Dark chocolate contains calcium, potassium, sodium, magnesium and vitamins A, B1, C, D, and E. Magnesium components contained in dark chocolate is useful to provide a sense of relaxation so that it can control a gloomy mood and relax muscles [6].

\section{RESEARCH METHODS}

The design used in this research is Quasi experimental research design with one group pretest-posttest design. The population of research is all female students in SMAN 4 Sidoarjo who have complained about dysmenorrhea. The samples of study were female students who experienced dysmenorrhea and were willing to become the respondents. 30 respondents are divided into 2 groups; 15 respondents who were given ginger drink and 15 respondents who were given dark chocolate. Sample inclusion criteria are in 15-17 years old, menstrual pain occurs when menstruation begins lasting 24 hours to 72 hours, the respondents do not use analgesic drugs or other medicines to reduce menstrual pain. The sampling technique uses quota sampling. The research instrument in the data collection uses pain measurement sheet with Numeric Rating Scale Scale.

This study was conducted for 3 days before menstruation and 3 days during menstruation in 2 months. The independent variable is ginger drink intake which is made of 10 grams of red ginger, 10 grams of brown sugar and $400 \mathrm{ml}$ of water. The water is then boiled. Herb ingredients that have been boiled are left into $200 \mathrm{ml}$ so the sample only drink $200 \mathrm{ml}$ of ginger drink. The other variable is dark chocolate (black chocolate) which is made of $40 \mathrm{gr}$ dark chocolate. The dark chocolate drink is given once a day in 3 days before menstruation and 3 days after menstruation. The difference value of pretest and posttest is tested using paired sample test with significant value $0.05 \%$ which means $95 \%$ confidence value. This study uses the instrument in the form of observation sheet and interview sheet. The measuring instrument is used for freevariable / dependentvariable. The pain intensity in primary dysmenorrhea is in scale of $1-10$.

\section{RESULTS AND DISCUSSION}

3.1 Measurement Result of DysmenorrheaIntensityon Female Student beforeconsuming Ginger Drink. Based on the observation and measurement of pain intensity using Numeric Rating Scale (1-10 pain scale), the result obtained are as follows: 
Tabel 1. Frequency Distribution of Respondents Based on Dysmenorrhealntensity Before Consuming Drink Ginger

\begin{tabular}{ccc}
\hline Scale & Frequency & Percentage (\%) \\
\hline 4 & 8 & 53.3 \\
5 & 4 & 26.7 \\
6 & 3 & 20 \\
\hline Total & 15 & 100 \\
\hline
\end{tabular}

Tabel 1 shows that the intensity of pain felt by the respondents before consuming ginger drink is mostly on scale 4 that is $53.3 \%$.

\subsection{The Measurement Results of Dysmenorrhea Intensityon Female Students Before consuming Black Chocolate}

Tabel 2.The Distribution Frequency of Respondents Based on Dysmenorrhea IntensityBefore consuming Dark chocolate

\begin{tabular}{ccc}
\hline Scale & Frequency & Percentage (\%) \\
\hline 4 & 5 & 33.3 \\
5 & 6 & 40.0 \\
6 & 4 & 26.7 \\
\hline Total & 15 & 100 \\
\hline
\end{tabular}

Table 2 showed that the intensity of pain felt by the respondents before consuming dark chocolate ins on scale 5 that is $40 \%$.

\subsection{The Measurement Results of Dysmenorrhea Intensityon Female Students After consuming Ginger Drinks}

Tabel 3. The Distribution Frequency of Respondents Based on Dysmenorrhea IntensityAfterconsuming Ginger Drinks

\begin{tabular}{ccc}
\hline Scale & Frequency & Percentage (\%) \\
\hline 1 & 1 & 6.7 \\
2 & 6 & 40.0 \\
3 & 8 & 53.3 \\
\hline Total & 15 & 100 \\
\hline
\end{tabular}

Table 3 shows that the intensity of pain felt by the respondents after consuming ginger drink is mostly located on scale 3 that is $53.3 \%$. It is obtained a decrease in pain intensity from moderate pain to mild pain.

\subsection{The Measurement Results of Dysmenorrhea Intensityon Female Students After consuming Dark chocolate}

Tabel 4. DistributionFrequency of Respondents Based on Dysmenorrhea IntensityAfter consuming Dark chocolate

\begin{tabular}{ccc}
\hline Scale & Frequency & Persentage (\%) \\
\hline 1 & 5 & 33.3 \\
2 & 7 & 46.7 \\
3 & 3 & 20.0 \\
\hline Total & 15 & 100 \\
\hline
\end{tabular}


Table4 shows that the intensity of pain felt by respondents after consuming dark chocolateis on scale 2 that is $46.7 \%$. The pain intensity decreases from moderate pain to mild pain.

\subsection{Paired Sample Test Results}

Tabel 5. The Relations of Pain Intensity Measurement before consuming and After consuming Ginger Drinking

\begin{tabular}{llll}
\hline Variables & N & Correlation & Sig \\
\hline Ginger Drink pre-post & 15 & 0.592 & 0.020 \\
\hline
\end{tabular}

Table5 shows that there is correlation between dysmenorrhea intensityand the consumption ginger drink. It can be seen from significant value of $\alpha=0.020<\alpha 0.05$. However, the strength of the relation is seen from the correlation strength that is 0.592 .

Tabel 6. The Results of Relations Pain Intensity Measurementbefore consuming and After consuming Dark Chocolate.

\begin{tabular}{llll}
\hline Variables & N & Correlation & Sig \\
\hline Dark Chocolatepre-post & 15 & 0.225 & 0.421 \\
\hline
\end{tabular}

Table 6 shows that there is no correlation between of dysmenorrhea intensity and the consumption of dark chocolate. It can be seen from significant value of $\alpha=0.421>\alpha$ 0.05 . However, the relation strength is low which is seen from the correlation strength that is 0.225 .

The provision of ginger and dark chocolate drink is to see the effect of the decreasingdysmenorrhea intensitybefore and after the treatment given to the respondent. The observation and measurement of pain intensity use a pain scale of 0-10 of Numeric Rating Scaleto all the respondents (adolescents). The results of the study found that before consuming ginger drink, 8 female students $(53.3 \%)$ had moderate menstrual pain. However, after consuming ginger drink, the pain scale of 8 students $(53.3 \%)$.was decreased from moderate pain to mild pain.

Moderate pain experienced by female students during menstruation can be caused by many things, one of which can be related to endocrine hormone that is by the increasing levels of prostaglandins. At the time of menstruation, the outermost portion decays and concerns other layers that can cause pain so that pain can arise as a reaction to the release of prostaglandins that become inflammatory mediators. The occurrence of menstrual pain (dysmenorrhea) due to the prostaglandin hormone makes the uterine muscles (uterus) to contract [7]. In this condition, it is still reasonable if dysmenorrhea is light and the person still can move.

However, when the dysmenorrhea occurs very severe and even interfere the activity, it is called as a disorder. Dysmenorrhea can be felt in the lower pelvic region, the waist, and can even spread up to the back [8]. In addition, menstrual pain that often occurs on the first day of menstruation or before the first day of menstruation is categorized as functional menstrual pain. This pain occurs as the result of the pressure on the cervical canal or cervix. Dysmenorrheausually will disappear or getting better over the next day of menstruation[9]. The causes of dysmenorrhea that occurs in female students can also be caused due to psychiatric or stress factors, such as when the students will have a test or when they have problems during menstruation. There is usually a sense like diarrhea, abdominal pain and other painwhich is transferred to 
dysmenorrhea pain. Thus, in addition to the occasional decay of prostaglandins, psychological factors or stress that occur will also increase the pain excitatory threshold so that the pain will increase and psychological factors or stress can also decrease the pain resistance [2].Ginger can be used to reduce dysmenorrhea. Beside, ginger is easy to get and ginger drink ingredients is easy to make. Ginger contains several nutritious substances that can relieve pain and nausea during menstruation. In addition, red ginger contains a substance which can stop the work of prostaglandin. Prostaglandin causes inflammation of blood vessels and it will send the pain to occur. Therefore, the pain which is experienced by respondents at the time of menstruation, becomes lighter after drinking red ginger. By stopping prostaglandin which is the cause of pain and inflammation of blood vessels and relieve cramps is a ginger treatment system that can be used to overcome the pain caused by menstruation [10].

Zingeron, gingerol and shagol are some of the chemical components found in ginger. These components provide pharmacological and physiological effects such as non-toxic and non-mutagenic even thoughit is at high concentrations, anti-oxidants, antiinflammatory, anti-carcinogenic and analgesic. Ginger also contains substances that can be efficacious relieve pain and nausea during menstruation / menstruation. Empirically, ginger also commonly used as a cure for colds, analgesics, indigestion, antiinflammatory and anti piretik [10]. However, the results of dysmenorrheaintensity before consuming dark chocolate showed that six students (40\%) students experienced dysmenorrhea with moderate pain and after consuming dark chocolate the pain scale of seven students $(46.7 \%)$ is decreased from moderate to mild.Pain is an unpleasant and subjective feeling that can not be shared with others, even if every individual gets the same stimulus. The stimulus of uterine contractions and endometrial tissue ischemia is due to excessive secretion of prostaglandins, but the reactions shown by each person are different. Byconsuming chocolate, there is a decrease of pain from moderate to mild levels [11].

Consuming dark chocolate can increases the secretion of serotonin, resulting in transmission to the dorsal corners (a part of body in where the sensory fibers of peripheral pain ends) so it will inhibit the transmission of pain. Serotonin will also keep the gate of pain closing. Serotonin deficiency will increase the sensitivity to the increased pain. Body can be stimulated to increase serotonin levels. Consuming dark chocolate will trigger the expenditure of endorphins, a substance conducting excitation of brain analgesia system. This endorphin will inhibit enzimsic ossigenase not to form PGG2. PGG2 is a substance which will form PGF2 alpha which is a pain me diator substance.

The likelihood of serotonin endorphin with serotonin, which is the presence of carbohydrates that contribute to elevated serotonin levels and biofeedback mechanisms of increased serotonin to increase carbohydrate intake in the body, this carbohydrate plays a role to trigger endorphin expenditure. The gate control theory can explain the mechanism of pain reduction. In the mechanism, the intensity of pain is lowered by blocking the pain impulse by endorphins which is triggered by consuming dark chocolate beside to the impulse barrier of pain by serotonin painless conditions which can not be passed on to dorsal corns [12]. The result of Paired Sample Test on the relations of measurement result of dysmenorrheaintensity before and afterconsuming ginger drink showed a significant value of $\alpha 0.020<\alpha 0.05$. It means that there is a relation of pain intensity before and after consuming ginger drink with medium strength relation, that is 0.592 . However, the results of paired sample test showed there is no 
correlation result of measurement of dysmenorrhea intensity before and after consuming dark chocolate because the significant value is $\alpha 0.421>\alpha 0.05$. It means there is no relation of pain intensity before and after consuming dark chocolate with low strength relation, that is 0.225 .

The results of this study indicate that consuming ginger drink can decrease pain intensity better than consuming dark chocolate. This is probably due to the chemical content of gingerol in ginger that is able to block prostaglandins. Prostaglandin hormones can cause inflamed blood vesselsrelieve cramps and can also cause pain that can reduce pain during menstruation. In addition, ginger also contains active components of non volatile phenols such as shogaol, zingeron, and gingerol which can be used as an antioxidant and to relieve pain. [3].

\section{CONCLUSION}

This study identifies the decrease of dysmenorrheapain by using nonpharmacological therapy of ginger drink and dark chocolate. In addition, this study also compared differences in effectiveness of the affect of ginger drinks and dark chocolate in decreasing dysmenorrhea by using the Numeric rating scale. The results of research showsthat before and after consuming ginger and dark chocolate, there is a difference of dysmenorrheaintensity. The result also shows that there is difference of pain intensity by consuming ginger drink and dark chocolate. The relation of pain intensity before and afterconsuming ginger drink is in medium strength. However, the pain intensity before and after consuming dark chocolate showed that there is no relation in dysmenorrheaintensity. It means that the pain intensity before and afterconsuming dark chocolate is low strength. Therefore, the results showed that ginger is more effective in decreasing pain intensity better than dark chocolate.

\section{REFERENCES}

C.-H. Tu, D. M. Niddam, T.-C. Yeh, J.-F. Lirng, C.-M. Cheng, C.-C. Chou, H.-T. Chao, and J.-C. Hsieh, "Menstrual pain is associated with rapid structural alterations in the brain," Pain, vol. 154, no. 9, pp. 1718-1724, 2013.

G. Grandi, S. Ferrari, A. Xholli, M. Cannoletta, F. Palma, C. Romani, A. Volpe, and A. Cagnacci, "Prevalence of menstrual pain in young women: What is dysmenorrhea?," J. Pain Res., vol. 5, pp. 169-174, 2012.

G. Ozgoli, M. Goli, and F. Moattar, "Comparison of Effects of Ginger, Mefenamic Acid, and Ibuprofen on Pain in Women with Primary Dysmenorrhea," J. Altern. Complement. Med., vol. 15, no. 2, pp. 129-132, 2009.

J. L. Riley III, M. E. Robinson, E. a Wise, and D. Price, "A meta-analytic review of pain perception across the menstrual cycle," Pain, vol. 81, no. 3, pp. 225-235, 1999.

J. W. Daily, X. Zhang, D. S. Kim, and S. Park, "Efficacy of Ginger for Alleviating the Symptoms of Primary Dysmenorrhea: A Systematic Review and Meta-analysis of Randomized Clinical Trials," Pain Med., vol. 16, no. 12, pp. 2243-2255, 2015.

K. Singletary, “Ginger,” Nutr. Today, vol. 45, no. 4, pp. 171-183, 2010.

K. Vincent, C. Warnaby, C. J. Stagg, J. Moore, S. Kennedy, and I. Tracey, "Dysmenorrhoea is associated with central changes in otherwise healthy women," Pain, vol. 152, no. 9, pp. 1966-1975, 2011.

Mardilah, "Faktor-Faktor yang Mempengaruhi Pengetahuan Remaja Putri Dalam 
Menghadapi Menarche di SMP Negeri 5 Darul Makmur."

M. De Tommaso, "Pain perception during menstrual cycle," Curr. Pain Headache Rep., vol. 15, no. 5, pp. 400-406, 2011.

P. Amelia, "Effect of Ginger Drinks on Nausea Vomiting in The First Trimester of Pregnancy," in IOP Conference Series: Materials Science and Engineering, 2017.

P. Rahnama, A. Montazeri, H. F. Huseini, S. Kianbakht, and M. Naseri, "Effect of Zingiber officinale R. Rhizomes (ginger) on pain relief in primary dysmenorrhea: A placebo randomized trial," BMC Complement. Altern. Med., vol. 12, 2012. 